\title{
A Modified Model for Nonlinear Fatigue Damage Accumulation of Turbine Disc Considering the Load Interaction Effect
}

\author{
Tudi Huang ${ }^{1,2}$, Ru-Chang Ding ${ }^{1,2}$, Yan-Feng $\mathrm{Li}^{1,2, *}$, Jie Zhou ${ }^{1,2}$ and Hong-Zhong Huang ${ }^{1,2}$ \\ 1 Mechanical and Electrical Engineering, University of Electronic Science and Technology of China, \\ Chengdu 611731, China \\ 2 Center for System Reliability and Safety, University of Electronic Science and Technology of China, \\ Chengdu 611731, China \\ * Correspondence: yanfengli@uestc.edu.cn; Tel.: +86-28-6183-1252
}

Received: 15 July 2019; Accepted: 19 August 2019; Published: 22 August 2019

\begin{abstract}
Fatigue damage accumulation theory is one of the core contents in structure fatigue strength design and life prediction. Among them, the nonlinear damage model can overcome the shortcomings of the linear damage model, which takes the loading sequence effect into account. Besides, the loading interaction cannot be ignored for its profound influence in damage accumulation behavior. In the paper, some commonly-used methods of the linear and nonlinear fatigue damage accumulation theory are investigated. In particular, a modified nonlinear fatigue damage accumulation model which considers the effects of loading sequences as well as loading interactions on fatigue life is developed, and a load interaction parameter is obtained by analyzing damage models which assumes that the load logarithm ratio between adjacent stress levels can characterize this phenomenon. Finally, the modified model is employed to predict the fatigue life of high pressure turbine disc. Moreover, comparison is made between the experimental data as well as the predicted lives using the Miner's rule, the Ye's model, and the modified model.
\end{abstract}

Keywords: nonlinear fatigue damage accumulation; life prediction; loading interaction; load sequence

\section{Introduction}

In engineering practice, most of the mechanical components are subjected to variable amplitude loadings, i.e., the peak-to-valley values of the loading varies with time. A large amount of test data has been accumulated so that the life data under constant loading can be converted equivalently by employing the fatigue damage accumulation theory, thus the fatigue life of structures under variable amplitude loading can be evaluated. Based on vast experiments and theoretical analysis, researchers proposed a variety of damage accumulation models. Among them, the linear fatigue damage accumulation model has a simple form and high computational efficiency which facilitates its engineering application, but also presents the following deficiencies [1,2]: (a) fails to consider loading history, (b) ignores relationship between damage and loading sequence, and (c) overlooks loading interaction effects. In order to overcome the abovementioned shortcomings, researchers have proposed some nonlinear fatigue accumulative damage theories. However, so far there is no comprehensive model that can take all of the aforementioned influencing factors into account [3]. The fatigue damage accumulation theory is also the core content of structural anti-fatigue design and life prediction. Therefore, it is very important to study the fatigue damage accumulation theory. In the study, a modified nonlinear fatigue damage accumulation model considering load interaction effects is developed. 


\section{Fatigue Damage Accumulation}

Fatigue is a failure mode where the materials' damage accumulation and property degraded under cyclic loading, and finally lead to fracture [4-6]. Damage is an important parameter to describe the change of material state in the process of fatigue failure which plays a key role in life prediction of mechanical components and structures. Existing damage accumulation models can be divided into linear damage accumulation theory and nonlinear damage accumulation theory [7]. The basic assumptions of the conventional fatigue damage accumulation theory are [7]:

(1) Fatigue damage may appear at materials or components at any cyclic stress amplitude above the fatigue limit. The severity of the fatigue damage is not only related to the stress amplitude effect times, but also related to the number of cycles that the material reaches to failure under this stress amplitude.

(2) The damage caused by each material or component at each stress amplitude is cumulative process, and the total damage accumulation, produced under different stress amplitude cycles, is equal to the sum of the damage at each stress level.

\subsection{Linear Fatigue Damage Accumulation Theory}

The theory of linear damage accumulation is commonly used because of its simplicity. The most commonly used one is the Miner linear damage rule. In 1945, Miner proposed a linear damage accumulation theory based on the work of Palmgren, referred to as Miner's rule [8]. Under multi-stage loading, the mathematical expression of Miner's rule is:

$$
D=\sum_{i=1}^{n} \frac{n_{i}}{N_{i}}=1
$$

where $D$ is the cumulative damage under l-level loading in total which equals to $1, n_{i}$ is the number of cycles under a given stress $\sigma_{i}$, and $N_{i}$ is the number of cycles under the same stress level to failure.

The experimental results [3-8] show that there is a large error between the results of the damage accumulation experiment and Miner's rule. In Miner's rule, loading levels are independent to each other, which ignores the loading sequence and loading interaction effect. Based on the Miner's rule, many researchers have proposed various modified linear damage accumulation theories including Grover's two-stage damage theory [9] and Manson's double linear damage rule [10], and Huang's fuzzy Miner rule [11,12].

The loading changes are very complex in the actual project, and other deterministic methods require a large number of test results to fit relevant parameters, and their prediction accuracy are generally lower than the Miner rule, thus the application of linear damage accumulation model is still in common use nowadays [13-15].

\subsection{Nonlinear Fatigue Damage Accumulation}

The nonlinear fatigue damage accumulation model, including the Marco-Starkey theory, Manson's damage curve approach, and Henry model, etc., compensates the inability of the linear damage accumulation model which could not consider the loading sequence effect on fatigue life [16-20]. However, as research progressed, more puzzles which have not solved before have gradually emerged [21-23]. First of all, the parameters in some models are difficult to determine thus require a large amount of test data for parameter fitting which makes the model not applicable to engineering practice. Moreover, nonlinear models are generally presented in the form of semi-empirical formulas, lacking physical significance, or failing to find the theoretical basis for the parameters in the model. The development and integration of damage mechanics has provided a good theoretical basis for the establishment of fatigue damage accumulation models presented an excellent description for the microscopic mechanism of fatigue, such as the Chaboche model [20], Corten-Dolan model [24] and 
Ye's model [25], these models have made great breakthroughs in fatigue life prediction. This paper classifies these nonlinear fatigue damage models into four categories.

\subsubsection{Nonlinear Fatigue Damage Accumulation Theory Based on Damage Curve Method:}

The definition of damage nonlinearity was first proposed by Marco and Starkey, which assumed that the damage shows an exponential relation of the cycle ratio, its expression is given as [26]:

$$
D \propto\left(\frac{n_{i}}{N_{i}}\right)^{x_{i}}
$$

where $x_{i}$ is a material parameter related to $i$ th loading level. This theory allows to correctly taking into account the effects of loading sequences.

Under two-stage variable amplitude loading, this model describes the fatigue damage accumulation well, and the damage rate increases with the rise of the number of cycles. However, it only provides a qualitative explanation, not specific formula for damage $D, x_{i}$ does not give a clear definition [27].

Later, Manson [17] developed different damage methods. Under multiple cyclic loadings, the Manson model is given as:

$$
D_{(A)}=\sum\left(\frac{n_{i}}{N_{i}}\right)^{q_{i}}, q_{i}=B N_{i}{ }^{\mu}
$$

where $B$ and $\mu$ both are material constants. Cumulative damage of fatigue $D_{(A)}$ is the total amount of damage.

The Manson model can predict the fatigue life under two-stage loadings accurately, but it is not suitable for fatigue life prediction under multi-stage loadings, and the concrete expression is not given. Manson-Halford improved the model based on the effective microscopic crack growth, but still cannot consider the loading interaction effect [2].

\subsubsection{Nonlinear Damage Accumulation Theory Considering Loading Interaction Effect:}

According to Corten-Dolan accumulation theory, the fatigue damage $D$ under constant amplitude loading for $n$ cycles can be calculated through:

$$
D=m r n^{a},
$$

where, $m$ is the number of material damage nuclear; $r$ is the damage evolution rate; $a$ is a testing constant. Under multi-stage loadings, the life formula can be derived as:

$$
N=\frac{N_{\max }}{\sum_{i=1}^{l} c_{i}\left(\sigma_{i} / \sigma_{\max }\right)^{b}}
$$

where $c_{i}$ is the percentage of circulation under cyclic stress $\sigma_{i}, \sigma_{\max }$ is the maximum stress, $N_{\max }$ is the number of cycle to failure under $\sigma_{\max }$, and the exponent $b$ is the material's sensitivity to stress loading history. The Corten-Dolan model is developed based on the modified S-N curve, which considers the loading interaction effect on fatigue life, In the Corten-Dolon model, a point corresponding to the highest level in the load history is selected as the reference point. The parameter $\left(\sigma_{i} / \sigma_{\max }\right)^{b}$ is used to describe the effects of loading interaction, which generally called the interaction factor. 
2.2.3. Nonlinear Damage Accumulation Theory Based on the Concept of Continuum Damage Mechanics

Chaboche [20] proposed a nonlinear continuum fatigue damage accumulation model, the expression is given as:

$$
d D=f\left(\sigma_{\max }, \sigma_{m}, D\right) d N,
$$

where $N$ is the number of cycles to failure, $\sigma_{\max }$ is the maximum stress, and $\sigma_{\mathrm{m}}$ is the average stress.

Consulting the Chaboche model, Fang et al. [28] proposed a continuum fatigue damage model based on the whole damage field measurement. Its expression is given as:

$$
\begin{gathered}
D=1-\left[1-\frac{n}{N_{f}}\right]^{\frac{1}{1-T}}, \\
T\left(\sigma_{\max }, \sigma_{m}\right)=1-\frac{1}{\mathrm{c} \ln \left|\sigma_{\max } / \sigma_{-1}\left(\sigma_{m}\right)\right|},
\end{gathered}
$$

where, $c$ is the material constant, and $\sigma_{-1}\left(\sigma_{m}\right)$ is the average stress fatigue limit.

The emerging damage mechanics research method has been applied to the field of fatigue research. The damage mechanics method uses the thermodynamics principle as the background, and establishes the evolution equation which characterizes the evolution law of the damage by means of strict mathematical and mechanical concepts. This model owns three main advantages. Firstly, it allows for the growth of damage below the initial fatigue limit when the material is subjected to prior cycling above the fatigue limit. Secondly, the model takes into account the influence of initial hardening effect by introducing a new internal variable which keeps memory of the largest plastic strain range in the prior loading history. Thirdly, mean stress effect is directly incorporated in the model. The shortcoming is that the theory is very strong and the material constant is difficult to determine, thus it is difficult to be applied to engineering practice.

\subsubsection{Nonlinear Damage Accumulation Theory Based on the Physical Property Degradation of Materials}

Ye [25] compared the variation of macroscopic mechanical parameters of metal materials with fatigue damage, and found that the toughness of materials decreases significantly with the increase of the number of load cycles. The effect of the cyclic loading on the static toughness, which is defined as the area under the stress-strain curve, is more evident than that on the other mechanical property parameters. The reduction of the static toughness in the fatigue damage process indicates the progressive exhaustion of the ability to absorb energy inherent in the material due to fatigue damage evolution, which directly associates with the irreversible process of energy dissipation of fatigue failure. Considering the exhaustion of the static toughness and dissipation of the plastic strain energy during fatigue failure, a damage variable consistent with the fatigue damage mechanism, sensitive to the fatigue damage process and can be measured with a simple experimental procedure is defined. In particular, the toughness dissipation model is given as:

$$
D=\frac{-\ln \left(1-\frac{n}{N_{f}}\right)}{\ln N_{f}} .
$$

Physically based on energy dissipation, Ye's model presents better life prediction accuracy for two-stage loading than the Miner linear model and the Manson model [25]. However, the model only contains one parameter in the final damage expression, the number of cycles $n$, without any other mechanical parameters. Actually, it is another form of exponential model. In particular, its advantage includes its simplicity in form and not requiring other testing constants, however, it still cannot consider the loading interaction effect. 
In addition to the above common damage accumulation models, the researchers established a number of damage accumulation models that reflect the development of fatigue damage by analyzing fatigue damage and failure mechanisms. However, due to the lack of a large number of experimental verifications and complex model formulas, their application is very narrow. In order to describe the damage evolution accurately, many methods were proposed to solve the problems of damage, such as the unified mechanics theory can be used to quantify damage without any empirical curves [29-36]. Otherwise, Yao [2] et al. and Fatemi [3] reviewed current fatigue damage accumulation theory and life prediction model 3. A modified model for nonlinear fatigue damage accumulation considering loading interaction effects

The fatigue damage of the component is not only related to the current loading, but also connected with the loading history. The loading interaction effect has a great influence on the fatigue life of the components [37-39]. Among them, by converting the form of damage accumulation, many nonlinear damage theories can effectively account the loading sequence effect, but they often ignore the loading interaction effect. Under variable amplitude loadings, whether under long-cycle loading spectrum or short-cycle loading spectrum, the loading interaction effect present great influence on the fatigue crack propagation of the components [40-43]. Some damage methods are shown in Table 1.

Table 1. Nonlinear damage accumulation theory.

\begin{tabular}{|c|c|c|c|}
\hline Method Categories & Model & Advantages & Disadvantages \\
\hline $\begin{array}{l}\text { Nonlinear fatigue } \\
\text { damage accumulation } \\
\text { theory based on damage } \\
\text { curve method }\end{array}$ & $\begin{array}{l}\text { Marco-Starkey theory [18] } \\
\text { Manson model [10] }\end{array}$ & $\begin{array}{l}\text { Considering the loading } \\
\text { level and loading } \\
\text { sequence, which is in } \\
\text { good agreement with the } \\
\text { results of the two-stage } \\
\text { loading test. }\end{array}$ & $\begin{array}{l}\text { Lack of consideration of loading } \\
\text { interaction effects, applications } \\
\text { under multi-stage or random } \\
\text { loadings have yet to be verified. }\end{array}$ \\
\hline $\begin{array}{l}\text { Nonlinear damage } \\
\text { accumulation } \\
\text { considering loading } \\
\text { interaction effect }\end{array}$ & $\begin{array}{l}\text { Corten-Dolan model [24] } \\
\text { Morrow's plastic work } \\
\text { interaction rule [18] }\end{array}$ & $\begin{array}{l}\text { Considering the } \\
\text { multi-stage loadings } \\
\text { interaction effects. }\end{array}$ & $\begin{array}{l}\text { Factors such as the number of } \\
\text { damaged nuclear are difficult to } \\
\text { determine, and a large number } \\
\text { of tests are required to obtain the } \\
\text { parameter of the Corten-Dolan } \\
\text { model }\end{array}$ \\
\hline $\begin{array}{l}\text { Nonlinear damage } \\
\text { accumulation theory } \\
\text { based on the concept of } \\
\text { continuum damage } \\
\text { mechanics }\end{array}$ & Chaboche model [20] & $\begin{array}{l}\text { It breaks through the } \\
\text { scope of the research of } \\
\text { Phenomenological } \\
\text { Science and has a } \\
\text { promising future. }\end{array}$ & $\begin{array}{l}\text { The theory is very strong, the } \\
\text { material constant is difficult to } \\
\text { be determined, and it is difficult } \\
\text { to promote the project at this } \\
\text { stage. }\end{array}$ \\
\hline $\begin{array}{l}\text { Nonlinear damage } \\
\text { accumulation theory } \\
\text { based on the physical } \\
\text { property degradation of } \\
\text { materials }\end{array}$ & $\begin{array}{l}\text { Ye's model [25] } \\
\text { Henry theory [19] }\end{array}$ & $\begin{array}{l}\text { good, the form is simple, } \\
\text { and no other experiment } \\
\text { constant is needed, } \\
\text { which reflects the effect } \\
\text { of loading sequence on } \\
\text { fatigue damage } \\
\text { accumulation. }\end{array}$ & $\begin{array}{l}\text { Due to the lack of consideration } \\
\text { of the loading interaction effect, } \\
\text { the model formula is more } \\
\text { complex and is not convenient } \\
\text { for engineering application. }\end{array}$ \\
\hline
\end{tabular}

Researches shown $[24,44]$ that the loading interaction effect can be characterized with the ratio of the loading level. Moreover, the greater the difference between the loading levels is, the more significant the interaction is. Under different loading sequences, sudden changes in the loading amplitude will cause the damage evolution of subsequent loading cycles to change, and then reduce the fatigue life of the structure. In addition, from the relational expressions of most fatigue life and stress, they have obvious logarithmic relationships [44].

Based on the above analysis, this paper defines the interaction factor as the ratio of the adjacent two-stage loading logarithm. The interaction factor under two-stage loading can be formulated as below:

$$
\omega_{1,2}=\frac{\ln \sigma_{1}}{\ln \sigma_{2}} .
$$


Between $D=F\left(n / N_{f}, \sigma\right)$ and $n / N_{f}$ can be described by power function, and introduce the interaction factor into the Ye's model to consider the loading interaction effect, and the modified model is shown as:

$$
D=\left[\frac{-\ln \left(1-\frac{n_{i}}{N_{f i}}\right)}{\ln N_{f i}}\right]^{\omega_{i}}, \omega_{i}=\frac{\ln \sigma_{i-1}}{\ln \sigma_{i}}, i \geq 2 .
$$

In general, the damage analysis and life prediction under variable amplitude loading are based on the equivalent damage, in other words, the material is considered to have an equivalent damage state at different loading levels [45]. The correlation between fatigue damage and stress levels is a necessary condition for sequential effects, so that the $D-n / N f$ curves at different stress levels are different.

For an effective fatigue damage accumulation model, it is necessary to solve the following problems [46]:

(a) For the material or structure, how much fatigue damage is caused by one stress level;

(b) How to quantify the fatigue damage accumulation under multiple stress levels;

(c) When the material or structure gets failure, how much the critical damage is. In order to verify its application, the predicted results employed the modified model are compared with the test results under variable amplitude loadings.

For constant loading, the damage is given as:

$$
D=\left[\frac{-\ln \left(1-\frac{n_{1}}{N_{f 1}}\right)}{\ln N_{f 1}}\right] .
$$

In this case, there is only one-stage cyclic loading, which means that the interaction between the different loading amplitude does not exist, thus the modified model can be simplified as the original model. For the two-stage loadings, according to the equivalence of fatigue damage, the stress $\sigma_{1}$ for $n_{1}$ cycles yields the equivalent damage $D_{1}$, which equal to the damage under $\sigma_{2}$ for $n_{2}{ }^{\prime}$ cycles.

$$
D_{1}=\left[\frac{-\ln \left(1-\frac{n_{1}}{N_{f 1}}\right)}{\ln N_{f 1}}\right]=\left[\frac{-\ln \left(1-\frac{n_{2}{ }^{\prime}}{N_{f 2}}\right)}{\ln N_{f 2}}\right]^{\frac{\ln \sigma_{1}}{\ln \sigma_{2}}}=\left[\frac{-\ln \left(\frac{n_{2}}{N_{f 2}}\right)_{g}}{\ln N_{f 2}}\right]^{\frac{\ln \sigma_{1}}{\ln \sigma_{2}}},
$$

where $(\bullet)_{g}$ is the residual damage.

Based on the equivalence of fatigue damage and Equation (13), we can get the residual damage:

$$
\left(\frac{n_{2}}{N_{f 2}}\right)_{g}=\left(\frac{1}{N_{f 2}}\right)^{\left[\frac{-\ln \left(1-\frac{n_{1}}{N}\right)_{f 1}}{\ln N_{f 1}}\right]} \frac{\ln \sigma_{2}}{\ln \sigma_{1}}
$$

The total damage under two-stage loading is obtained as:

$$
\begin{aligned}
& D=\left(1-\left(\frac{n_{2}}{N_{f 2}}\right)_{g}\right)+\frac{n_{2}}{N_{f 2}} \\
&= 1-\left(\frac{1}{N_{f 2}}\right)^{\left[\frac{-\ln \left(1-\frac{n_{1}}{N_{f 1}}\right)}{\ln N_{f 1}}\right]}+\frac{\ln \sigma_{2}}{\ln \sigma_{1}}+ \\
& N_{f 2}
\end{aligned}
$$


Similarly, the residual damage under multi-stage loading can be driven as:

$$
\left(\frac{n_{i}}{N_{f i}}\right)_{g}=\left(\frac{1}{N_{f i}}\right)^{\left[\frac{-\ln \left(\left(\frac{n_{i-1}}{N_{f i-1}}\right)-\frac{n_{i-1}}{N_{f i-1}}\right)}{\ln N_{f i-1}}\right]} \quad, i \geq 3 .
$$

The total damage under multi-stage loading is obtained as:

$$
\begin{aligned}
& D=\left(1-\left(\frac{n_{i}}{N_{f i}}\right)_{g}\right)+\frac{n_{i}}{N_{f i}}
\end{aligned}
$$

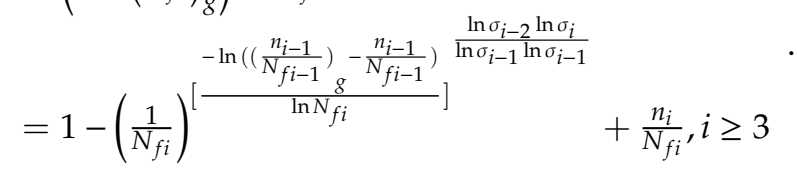

\section{Numerical Cases Validation}

In this section, predicted results using the modified model and the Miner's rule are compared with the test data. As a key component of the aero engine, the actual loading spectrum of high pressure turbine disc under working conditions is irregular. The high pressure turbine disc is cast by GH4133, the tensile properties is shown in Table $2[12,47,48]$.

Table 2. The tensile properties of high pressure turbine disc.

\begin{tabular}{ccccccc}
\hline $\begin{array}{c}\text { Elasticity } \\
\text { Modulus } \\
E(\mathrm{GPa})\end{array}$ & $\begin{array}{c}\text { Poisson's } \\
\text { Ratio } \\
\mu\end{array}$ & $\begin{array}{c}\text { Yielding } \\
\text { Stress } \\
\sigma_{y}(\mathrm{MPa})\end{array}$ & $\begin{array}{c}\text { Strength } \\
\text { Limit } \\
\sigma_{\boldsymbol{u}}(\mathrm{MPa})\end{array}$ & $\begin{array}{c}\text { Reduction } \\
\text { of Area } \\
\varphi(/ \%)\end{array}$ & $\begin{array}{c}\text { Coefficient } \\
\text { of Linear } \\
\text { Expansion } \\
\boldsymbol{\alpha}\left(\times \mathbf{1 0}^{-6} /{ }^{\circ} \mathrm{C}\right)\end{array}$ & $\begin{array}{c}\text { Density } \\
\left(\mathbf{k g} / \mathbf{m}^{3}\right)\end{array}$ \\
\hline 220 & 0.36 & 878 & 1221 & 31 & 12.0 & 8210 \\
\hline
\end{tabular}

Under the multi-stage loadings, the loading interaction effect has a great influence on the formation and growth of the fatigue cracks of the disc, which in turn affects the fatigue life of the disc. The initiation and propagation of the fatigue cracks of the disc is not only related to the current stress level, but also the previous stress level. According to the rotational speed, the loading spectrum can be divide into three states: "0-maximum continue-0", "idle-maximum continue-idle" and "cruise-maximum continue-cruise". The fatigue life prediction is performed using the modified nonlinear fatigue damage accumulation model considering the loading interaction effect, as shown in Table 3.

Table 3. Field loading spectrum and fatigue damage of high pressure turbine disc in $750 \mathrm{~h}$.

\begin{tabular}{cccc}
\hline States & $\begin{array}{c}\text { S1: 0-Maximum } \\
\text { Continue-0 }\end{array}$ & $\begin{array}{c}\text { S2: Idle-Maximum } \\
\text { Continue-Idle }\end{array}$ & $\begin{array}{c}\text { S3: Cruise-Maximum } \\
\text { Continue-Cruise }\end{array}$ \\
\hline$\sigma_{\max }(\mathrm{MPa})$ & 932.14 & 932.14 & 932.14 \\
$\sigma_{\mathrm{a}}(\mathrm{MPa})$ & 466.007 & 327.475 & 52.015 \\
$\gamma$ & 0.663 & 0.663 & 0.663 \\
$n_{i}$ & 1278 & 1936 & 23,326 \\
$N_{f i}$ & 22,831 & 70,041 & $+\infty$ \\
$D=n_{i} / N_{f i}$ & 0.056 & 0.0276 & 0 \\
\hline
\end{tabular}

Based on Table 3, the fatigue damage of "cruise-maximum continue-cruise" is 0 , and it can be considered that the high pressure turbine disc operates under two-stage loading. In order to considering the mean stress effect, the Walker model is employed to obtain the equivalent stress, which is more suitable than other models [49]. The Walker exponent $\gamma$ is an adjustable constant associated 
with the material properties, which can provide a good correction and sensitivity of mean stress, and it can be determined by [49]:

$$
\gamma=0.5+\frac{\sigma_{u}-\sigma_{y}}{\sigma_{u}+\sigma_{y}}=0.663
$$

According to the Walker model [48] and Table 3, the equivalent stress of "0-maximum-0" is:

$$
\sigma_{1}=\sigma_{\max }^{1-\gamma} \sigma_{a}^{\gamma}=932.14^{0.337} \times 466.007^{0.663}=588.653 \mathrm{MPa}
$$

Similarly, the equivalent stress of "idle-maximum continue-idle" is:

$$
\sigma_{2}=\sigma_{\max }^{1-\gamma} \sigma_{a}^{\gamma}=932.14^{0.337} \times 327.475^{0.663}=465.884 \mathrm{MPa} .
$$

Therefore, the high pressure turbine disc can be seen that it is served under "588.653-465.884 MPa" two-stage loading. The nonlinear fatigue damage accumulation model with the loading interaction effect is employed to predict the damage of high pressure turbine disc under two-stage loading, as listed in Table 4.

Table 4. Fatigue damage of high pressure turbine disc under external loading spectrum of $750 \mathrm{~h}$.

\begin{tabular}{ccccccc}
\hline $\begin{array}{c}\text { The Loading Stress } \\
(\mathrm{MPa})\end{array}$ & $n_{1}$ & $\frac{n_{1}}{N_{f 1}}$ & $n_{2}$ & $\frac{n_{2}}{N_{f 2}}$ & $\begin{array}{c}\text { Miner Model } \\
\frac{n_{1}}{N_{f 1}}+\frac{n_{2}}{N_{f 2}}\end{array}$ & $\begin{array}{c}\text { Modified Model } \\
1-\left(\frac{n_{2}}{N_{f 2}}\right)+\frac{n_{2}}{N_{f 2}}\end{array}$ \\
\hline $588.563-465.884$ & 1278 & 0.056 & 1936 & 0.0276 & 0.0836 & 0.1022 \\
\hline
\end{tabular}

According to the calculation of the cumulative fatigue damage of the high pressure turbine disc, the fatigue life can be obtained as:

$$
t=750 \frac{1}{D}=7339 \mathrm{~h}
$$

Comparing with the fatigue life of high pressure turbine discs provided by the engine plant, $T s=7000 \mathrm{~h}$, the estimated error of modified model is $4.84 \%$, the estimated error of Ye's model is $19.59 \%$, and the predicted error using the Miner model is $28.16 \%$, the results showed that modified model is more accurate than Miner model and Ye's model.

\section{Conclusions}

This paper discussed some commonly-used methods about the linear damage theory and nonlinear damage accumulation in engineering. The interaction factor is defined as the ratio of the adjacent two-stage loading logarithm, and is introduced into the material toughness dissipative damage model. In particular, the modified model considers the loading sequence and loading interaction effects on fatigue life. Finally, an example is provided to verify the capability of the modified model, the results show that modified model is more accurate than Miner model and the Ye's model.

Author Contributions: Formal analysis, T.H.; investigation, R.-C.D.; methodology, T.H. and J.Z.; project administration, H.-Z.H.; supervision, H.-Z.H.; validation, Y.-F.L.; writing-original draft, T.H.; writing-review \& editing, H.-Z.H.

Funding: This research was funded by National Natural Science Foundation of China, grant number 51775090.

Conflicts of Interest: The authors declare no conflict of interest.

\section{References}

1. Xu, B. Fatigue Strength; Higher Education Press: Beijing, China, 1988.

2. Yang, X.H.; Yao, W.X.; Duan, C.M. Theoretical progress of deterministic fatigue cumulative damage. Eng. Sci. 2003, 5, 81-87. 
3. Fatemi, A.; Yang, L. Cumulative fatigue damage and life prediction theories: A survey of the state of the art for homogeneous materials. Int. J. Fatigue 1998, 20, 9-34. [CrossRef]

4. Mi, J.; Li, Y.F.; Yang, Y.J.; Peng, W.; Huang, H.Z. Reliability assessment of complex electromechanical systems under epistemic uncertainty. Reliab. Eng. Syst. Saf. 2016, 152, 1-15. [CrossRef]

5. Mi, J.; Li, Y.F.; Peng, W.; Huang, H.Z. Reliability analysis of complex multi-state system with common cause failure based on evidential networks. Reliab. Eng. Syst. Saf. 2018, 174, 71-81. [CrossRef]

6. Li, H.; Huang, H.Z.; Li, Y.F.; Zhou, J.; Mi, J. Physics of failure-based reliability prediction of turbine blades using multi-source information fusion. Appl. Soft Comput. 2018, 72, 624-635. [CrossRef]

7. Yuan, X.; Li, X.M. Research status and development of forecast methods of fatigue life. Aviat. Manuf. Technol. 2005, 12, 80-84.

8. Miner, M.A. Cumulative damage in fatigue. J. Appl. Mech. 1945, 12, 159-164.

9. Grover, H.J. An Observation Concerning the Cycle Ratio in Cumulative Damage. In Symposium on Fatigue of Aircraft Structures; Subcommittee, V., Ed.; ASTM International: West Conshohocken, PA, USA, 1960; pp. 120-124.

10. Manson, S.S.; Freche, J.C.; Ensign, C.R. Application of a Double Linear Damage Rule to Cumulative Fatigue. In Fatigue Crack Propagation; Grosskreutz, J., Ed.; ASTM International: West Conshohocken, PA, USA, 1967; pp. 384-412.

11. Zhu, S.P.; Huang, H.Z.; Xie, L.Y. The prediction theory of fuzzy fatigue life with small load reinforcement. Chin. J. Aeronaut. 2009, 30, 1048-1052.

12. Lv, Z. Research on Low Cycle Fatigue Life Prediction Methodology of Aero-Engine Disc. Ph.D. Thesis, University of Electronic Science and Technology of China, Chengdu, China, 6 January 2016.

13. Li, Y.F.; Huang, H.Z.; Mi, J.; Peng, W.; Han, X. Reliability analysis of multi-state systems with common cause failures based on Bayesian network and fuzzy probability. Ann. Oper. Res. 2019. [CrossRef]

14. Zhang, X.; Gao, H.; Huang, H.Z.; Li, Y.F.; Mi, J. Dynamic reliability modeling for system analysis under complex load. Reliab. Eng. Syst. Saf. 2018, 180, 345-351. [CrossRef]

15. Li, X.Y.; Huang, H.Z.; Li, Y.F.; Zio, E. Reliability assessment of multi-state phased mission system with non-repairable multi-state components. Appl. Math. Model. 2018, 61, 181-199. [CrossRef]

16. Zhang, D.C. Research on the Accumulation Theory of Multi-Axis Fatigue Damage. Master's Thesis, Nanjing University of Aeronautics and Astronautics, Nanjing, China, 1 December 2010.

17. Manson, S.S.; Halford, G.R. Practical implementation of the double linear damage rule and damage curve approach for treating cumulative fatigue damage. Int. J. Fract. 1981, 17, 169-192. [CrossRef]

18. Marco, S.M.; Starkey, W.L. A concept of fatigue damage. Trans. ASME 1954, 76, 627-632.

19. Henry, D.L. A theory of fatigue damage accumulation in steel. Trans. ASME 1955, 77, 913-918.

20. Chaboche, J.L.; Lesne, P.M. A non-linear continuous fatigue damage model. Fatigue Fract. Eng. Mater. Struct. 1988, 11, 1-17. [CrossRef]

21. Li, X.Y.; Li, Y.F.; Huang, H.Z.; Zio, E. Reliability assessment of phased-mission systems under random shocks. Reliab. Eng. Syst. Saf. 2018, 180, 352-361. [CrossRef]

22. Zheng, B.; Li, Y.F.; Huang, H.Z. Intelligent fault recognition strategy based on adaptive optimized multiple centers. Mech. Syst. Signal Process. 2018, 106, 526-536. [CrossRef]

23. Huang, C.G.; Huang, H.Z.; Li, Y.F. A bi-directional LSTM prognostics method under multiple operational conditions. IEEE Trans. Ind. Electron. 2019, 66, 8792-8802. [CrossRef]

24. Corten, H.T.; Dolan, T.L. Cumulative Fatigue Damage. In Proceedings of the International Conference on Fatigue of Metals, New York, NY, USA, 28-30 November 1956; Institution of Mechanical Engineers, ASME: London, UK; pp. 235-246.

25. Ye, D.Y.; Wang, D.J.; Tong, X.Y.; Yao, L.J. A new quantitative method of fatigue damage based on material toughness dissipation. Exp. Mech. 1999, 1, 80-88.

26. Li, S.M. Mechanical Fatigue and Reliability Design; Science Press: Beijing, China, 2006.

27. Liu, R.T.; He, B.Q. Fatigue life prediction under variable loading conditions. Acta Armamentarii 1994, 4, $43-47$.

28. Fang, Y.Q.; Hu, M.M.; Luo, Y.L. A continuous fatigue damage model based on the whole domain damage test. J. Mech. Strength 2006, 28, 582-586.

29. Tang, H.; Basaran, C. Influence of microstructure coarsening on thermomechanical fatigue behavior of $\mathrm{Pb} / \mathrm{Sn}$ eutectic solder joints. Int. J. Damage Mech. 2001, 10, 235-255. [CrossRef] 
30. Yao, W.; Basaran, C. Computational damage mechanics of electromigration and thermomigration. J. Appl. Phys. 2013, 114, 103708. [CrossRef]

31. Basaran, C.; Nie, S. A thermodynamics based damage mechanics model for particulate composites. Int. J. Solids Struct. 2007, 44, 1099-1114. [CrossRef]

32. Amiri, M.; Khonsari, M.M. On the role of entropy generation in processes involving fatigue. Entropy 2012, 14, 24-31. [CrossRef]

33. Naderi, M.; Amiri, M.; Khonsari, M.M. On the thermodynamic entropy of fatigue fracture. Proc. R. Soc. A 2009, 466, 423-438. [CrossRef]

34. Sosnovskiy, L.; Sherbakov, S. Mechanothermodynamic entropy and analysis of damage state of complex systems. Entropy 2016, 18, 268. [CrossRef]

35. Sosnovskiy, L.; Sherbakov, S. A model of mechanothermodynamic entropy in tribology. Entropy 2017, $19,115$. [CrossRef]

36. Sosnovskiy, L.; Sherbakov, S. Mechanothermodynamics; Springer International Publishing: Cham, Switzerland, 2016.

37. Hua, G.; Fernando, U.S. Effect of non-proportional overloading on fatigue life. Fatigue Fract. Eng. Mater. Struct. 2010, 19, 1197-1206. [CrossRef]

38. Skorupa, M. Load interaction effects during fatigue crack growth under variable amplitude loading-A literature review. Part I: Empirical trends. Fatigue Fract. Eng. Mater. 1998, 21, 987-1006. [CrossRef]

39. Schaff, J.R.; Davidson, B.D. Life prediction methodology for composite structures. Part I—Constant amplitude and two-stress level fatigue. J. Compos. Mater. 1997, 31, 128-157. [CrossRef]

40. Wang, D.J.; Ping, A.; Xu, H. Criteria for compiling fatigue load spectrum. J. Mech. Strength 1993, 4, 37-40.

41. Wang, D.J.; Ping, A. The processing of random fatigue load and the preparation of load spectrum. J. Northeast. Univ. Nat. Sci. Ed. 1994, 4, 327-331.

42. Golos, K. Cumulative fatigue damage. Mater. Sci. Eng. A 1988, 104, 61-65. [CrossRef]

43. Bui-Quoc, T.; Choquet, J.A.; Biron, A. Cumulative fatigue damage on large steel specimens under axial programmed loading with nonzero mean stress. J. Eng. Mater. Technol. 1976, 98, 249-255. [CrossRef]

44. Zhang, A.; Bui-Quoc, T.; Gomuc, R. A procedure for low cycle fatigue life prediction for various temperatures and strain rates. J. Eng. Mater. Technol. 1990, 112, 422-428. [CrossRef]

45. Xie, L.Y. The equivalence of fatigue damage state. J. Mech. Strength 1995, 2, 100-104.

46. Xia, T.X.; Yao, W.X. Comparative research on the accumulative damage rules under multiaxial block loading spectrum for 2024-T4 aluminum alloy. Int. J. Fatigue 2013, 48, 257-265. [CrossRef]

47. Shi, C.X.; Yan, M.G.; Zhu, Z.Q. China Aeronautical Materials Handbook; Standards Press of China: Beijing, China, 2001.

48. Lv, Z.; Huang, H.Z.; Wang, H.K.; Gao, H.; Zuo, F.J. Determining the Walker exponent and developing a modified Smith-Watson-Topper parameter model. J. Mech. Sci. Technol. 2016, 30, 1129-1137. [CrossRef]

49. Dowling, N.E.; Calhoun, C.A.; Arcari, A. Mean stress effects in stress-life fatigue and the Walker equation. Fatigue Fract. Eng. Mater. Struct. 2009, 32, 163-179. [CrossRef]

(C) 2019 by the authors. Licensee MDPI, Basel, Switzerland. This article is an open access article distributed under the terms and conditions of the Creative Commons Attribution (CC BY) license (http://creativecommons.org/licenses/by/4.0/). 